Artículo

\title{
La educación con enfoque por competencias: ¿una oportunidad para impulsar la investigación en la universidad?
}

\author{
Competency-based education \\ ¿An opportunity to enhance research at the university? \\ René Antonio Chanta Martínez* \\ rene.chanta@udb.edu.sv \\ ISSN 1996-1642, Editorial Universidad Don Bosco, año 11, No.19, enero-junio de 2017, pp. 39-49 \\ Recibido: 9 de noviembre de 2016. Aprobado: 12 de enero de 2017
}

\begin{abstract}
Resumen
El presente texto es una reflexión sobre la enseñanza por competencias en al ámbito de la educación universitaria. Presentará brevemente, un análisis enfatizando que la educación por competencias puede ser la oportunidad para promover la tendencia investigativa en el aula. Hoy que el mundo se ha complejizado y se hacen diversos cambios y renovaciones, la educación por competencias se presenta como un reto y una oportunidad para fomentar la curiosidad investigativa. De esta menara, se facilitará la creación de un pensamiento propio, original y comprometido con la sociedad.
\end{abstract}

Palabras clave: educación, competencias, investigación, universidad.

\begin{abstract}
In this paper, the author reflects on a competency-based teaching in the university context. He develops the idea that competency-based education poses the opportunity to promote research in the university classroom. In doing that, the author overviews the idea of competence and how it responds to a complex changing world in which the traditional paradigms are no longer the answer. Competencybased education is presented as the opportunity to enhance research competencies to meet this challenging context.
\end{abstract}

Keywords: education, competence, research, university.

\footnotetext{
* Licenciado en Educación.

Para citar este artículo: Chanta, R. A. (2017). La educación con enfoque por competencias ¿Una oportunidad para impulsar la investigación en la universidad? Diá-logos 19, 39-49.
} 


\section{Introducción}

La educación ha estado siempre en constante proceso de cambio a lo largo de diversos momentos y en diversas sociedades. Además, continuamente proponen, debaten e implementan reformas, reorientaciones y nuevas perspectivas para la educación. La sociedad actual no es la excepción en eso. Hoy en día se enfatiza la necesidad de cambiar y modificar la forma de educar y es por eso que los sistemas educativos nacionales siempre tienen planes para renovar la educación. Desde ese punto de vista, en los últimos años se ha hablado de una educación y currículum por competencias en diferentes sistemas educativos (Zavala, 2007). Con esto, de hecho, se tienen que transformar los planes de estudio y programas educativos. Como en todo cambio o innovación, siempre hay muchas resistencias a la hora de implementar una educación basada en competencias. Ante esto, no hay que asustarse ni alarmarse. Es necesario recordar que los cambios en las sociedades humanas son procesos complejos que no se producen instantáneamente. Más bien, todo cambio implica procesos de recepción, asimilación y maduración.

Sin embargo, ahora que está la tendencia a organizar e implementar una educación por competencias, bien valdría la pena preguntarse, iHasta qué punto la enseñanza por competencias es la más adecuada para implementarse en los currículos escolares? El presente artículo no pretende responder totalmente a esa interrogante, aunque sí se la plantea como pretexto para la reflexión. De hecho, lo que se quiere en este escrito es cuestionarse profundamente sobre lo que es la educación por competencias y con base ello tomar las ventajas de este enfoque educativo como una oportunidad para promover la investigación en el aula.

Sin duda, la investigación ha sido una de las aéreas de los estudios universitarios que ha estado tradicionalmente marginada. Por lo general las instituciones de educación superior enfatizan la docencia y, en alguna medida, la proyección social. Pero la investigación ha sido una de las tareas históricamente abandonadas o poco potenciadas. Desde este punto, en este texto se demuestra que la educación por competencias puede ser un pilar fundamental para promover la curiosidad investigativa ya que se basa en que los alumnos son seres activos en su aprendizaje y en la consecución de logros académicos.

Se utiliza aquí los términos "tendencia investigativa" o "curiosidad investigativa" más que investigación en sí. Esto se debe a que la investigación en sentido estricto es un proceso largo y requiere inversión, presupuesto, seguimiento a las iniciativas y una entidad que lo coordine a corto y largo plazo. Todo esto desbordaría lo que es una asignatura, unas sesiones de clase o un ciclo académico. No obstante, los términos "tendencia investigativa" o "curiosidad investigativa" son más específicos y enfatizan que las sesiones de clase, una unidad temática

La educación con enfoque por competencias: ¿una oportunidad para impulsar la investigación

40. en la universidad? o una materia pueden ser un inicio o comienzo para realizar investigaciones y resolver problemas concretos y de esa manera despertar la chispa intelectual en los alumnos. 


\section{¿Qué es la educación por competencias?}

TEn este apartado no se busca dar una definición completa y exhaustiva de lo que es una educación por competencias, ya que mucho se ha escrito sobre esto y probablemente habrá hoy en día muy buenos estudios al respecto (Alegre De la Rosa y Villar, 2006). Sin embargo, es necesario hacer una aproximación teórica al respecto para tener algunos referentes. Hay que decir que competencias no es algo propio o específico de las ciencias de la educación. Otras disciplinas y ciencias ya han utilizado esta terminología desde hace varios años. Por ejemplo, es bien sabido que en las ciencias económicas continuamente se habla de competencia para enfatizar la eficiencia en una organización comercial. De esta manera, se dice que una empresa es competente cuando puede tomar las decisiones más acertadas para lograr crecer y satisfacer a las personas. En la actualidad, el Parlamento Europeo ha propuesto las competencias básicas que debe poseer toda persona entre las cuales estarían: la plena realización personal, la ciudanía activa, la cohesión social y la empleabilidad en la sociedad del conocimiento (Sacristán, 2008).

Pero, sin querer perder el enfoque educativo del término competencia, de acuerdo con un documento del Ministerio de Educación publicado hace aproximadamente diez años, competencia es "la capacidad de enfrentarse con garantías de éxito a tarea simples y complejas en un contexto determinado" (Ministerio de Educación, 2008). Dicho concepto de competencias siguió usándose en la educación nacional en diferentes momentos y textos educativos. Como bien se señala en un estudio, en el país se inició la implementación de enseñanzas por competencias con un programa denominado "COMPRENDO" en donde se pensaba desarrollar las competencias mínimas para matemáticas y lenguaje en alumnos del primer ciclo de educación básica. Desde ahí es que el concepto por competencias se definía como los aprendizajes esperados por los educandos al final de un proceso determinado (Represa, 2009). Si analizamos la concepción anterior, competencia sería un producto final, ya que apela a los aprendizajes de los alumnos al final de un tema, unidad, materia o año académico. Sin embargo, lo formativo también es importante y fundamental ya que el producto final no surge de la nada sino que ha habido previamente un proceso que lo ha puesto en marcha y le da continuidad.

Desde allí, es que el concepto "competencia" migró hacia el sistema educativo de educación superior. En efecto, hoy en día varias universidades privadas y la estatal están realizando nuevos programas de las asignaturas o nuevos planes de estudio con un enfoque por competencias. Sin duda, un proceso que le dio un empuje a esto fue el Proyecto Tuning. El proyecto Tuning, que ha sido impulsado tanto por países de América Latina como de Europa, tiene como meta mejorar la calidad, efectividad y transparencia en la educación superior a nivel latinoamericano. Al respecto un texto nos dice lo siguiente refiriéndose a la educación por competencias basándose en el proyecto Tuning:

Se buscará el desarrollo de perfiles profesionales con competencia deseables en términos de competencias genéricas y relativas a cada 
área de estudios incluyendo destrezas, conocimientos y contenidos genéricos dentro de las áreas de: Administración de Empresas, ciencias de la educación, Historia, Matemática, ya que las dos primeras cuentan con demanda en nuestro país (Rodríguez, 2012, p. 10).

La idea del proyecto Tuning es que los profesionales futuros sean competentes en su especialidad y capaces de enfrentarse a los retos que plantea ya un mundo globalizado. Ese mundo globalizado plantea cambios acelerados que cada vez demandan más especialización. Esa realidad actual demanda nuevos conocimientos y destrezas. La educación por competencias promete dar respuesta a eso. Desde ese punto, una definición bastante integral del concepto de competencia aplicado al mundo de la educación universitaria sería el siguiente:

Procesos complejos de desempeño con idoneidad en determinados contextos, integrando diferentes saberes (saber ser, saber hacer, saber conocer y saber convivir), para realizar actividades y/o resolver problemas con sentido de reto, motivación, flexibilidad, creatividad, comprensión y emprendimiento, dentro de una perspectiva de procesamiento metacognitivo, mejoramiento continuo y compromiso ético, con la meta de contribuir al desarrollo personal, la construcción y afianzamiento del tejido social, la búsqueda continua del desarrollo económico-empresarial sostenible, y el cuidado y protección del ambiente y de las especies vivas (Tobón, 2008, p. 17)

La educación basada en competencias abarca varios aspectos, desde los saberes teóricos, hasta la capacidad de resolver problemas, comprometiéndose con la sociedad. A la vez, se concibe la educación como un proceso dinámico y de mejora continua. Hoy en día, la educación y los currículos por competencias, aunque posiblemente no se están aplicando con rigurosidad en ciertas instituciones, ya que es algo relativamente reciente, si ha ayudado a crear una nueva sensibilidad y ya ha permeado el discurso educativo de varias universidades. De acuerdo con un estudio reciente, la importancia de un enfoque por competencias en la educación superior estribaría en los siguientes puntos:

Cuadro 1. ¿Por qué es importante la educación por competencias en el mundo universitario?

La educación con enfoque por competencias: ¿una oportunidad para impulsar la investigación

42. en la universidad? 


\begin{tabular}{ll}
\hline Elemento & Explicación \\
\hline $\begin{array}{l}\text { Aumento de la } \\
\text { pertinencia de los } \\
\text { programas educativos }\end{array}$ & $\begin{array}{l}\text { La educación por competencias busca orientar los aprendizajes hacia } \\
\text { los retos del mundo actual y problemas del contexto social. De esa } \\
\text { forma los aprendizajes y la evaluación adquieren sentido no solo para } \\
\text { los alumnos sino que también para los docentes y la sociedad. }\end{array}$ \\
\hline $\begin{array}{l}\text { Posibilita una gestión } \\
\text { de la calidad. }\end{array}$ & $\begin{array}{l}\text { La educación por competencias permite evaluar la calidad desde } \\
\text { dos frentes: evaluación de la calidad del desempeño y evaluación } \\
\text { de la calidad de la formación que brinda la institución educativa. }\end{array}$ \\
\hline $\begin{array}{l}\text { Política educativa } \\
\text { internacional }\end{array}$ & $\begin{array}{l}\text { La formación basada en competencias se está convirtiendo en una } \\
\text { política de alto alcance internacional. En efecto, varios países han } \\
\text { hecho reformas y planes siguiendo los currículos por competencias. }\end{array}$ \\
\hline Movilidad. & $\begin{array}{l}\text { La formación por competencias sería clave para facilitar la movilidad } \\
\text { de estudiantes, docentes, trabajadores y profesionales de diversos } \\
\text { países. }\end{array}$ \\
\hline
\end{tabular}

Fuente: Tobon, 2008.

\section{Fundamentos antropológicos de un enfoque por competencias}

Hablar de educación es forzosamente hablar del ser humano. Se puede afirmar que la educación es un aspecto inherente al ser humano y le acompaña toda la vida. De ahí que todo modelo educativo o enfoque de educación tiene una visión antropológica de la cual se sustenta y se condiciona. Por tal razón, en este apartado conviene preguntarse qué tipo de ser humano pretende formar una enseñanza por competencias. Aquí se hace referencia a dos aspectos, que de una u otra forma, fundamentarían la antropología de una enseñanza por competencias.

Un primer aspecto antropológico en el cual estaría anclada una enseñanza basada en competencias sería concebir al ser humano como un individuo "racional", "dinámico", en constante cambio y transformación. Ya varios filósofos han dicho que la persona humana no es una entidad estática, sino que es un ser dinámico y abierto a los demás. Heidegger por ejemplo hablaba que el ser humano es un "ser con otros" y Xavier Zubiri manifestaba que el ser humano es una esencia abierta (Zubiri, 1989). Si el ser humano es abierto y dinámico, la educación, al ser un producto humano también será así. En efecto, la educación no será algo inerte, estático o inamovible. Siempre estará en continuas mejoras, transformaciones e incluso retrocesos. Escritores sobre educación como Aníbal Ponce en su tradicional obra de tipo marxista Educación y luchas de clases decía que en cada modo de producción había una forma diferente de educar (Ponce, 2014). Jean Piaget -hoy muy leído por psicólogos y educadoresenfatizaba que el aprendizaje era diferente dependiendo de la edad del niño o adolescente. El enfoque por competencias parte de que el ser humano es cambiante y dinámico y, por tanto, la educación al ser un producto derivado de procesos humanos, debería responder a las necesidades y complejidades del mundo actual. Ya el texto del Ministerio de Educación dice: "la competencia se entiende ligado a la acción y como algo dinámico y no estático" (Ministerio de Educación, 2008, p. 7). 
Un segundo aspecto sería enfatizar que el ser humano es un ente limitado, contingente, finito y en búsqueda continua de nuevas situaciones. El ser humano es consciente que es finito (Oroz, 1988). Ya desde Kant se dijo que la razón humana es limitada. Todos tienen fortalezas y debilidades. Desde ese punto de vista, aplicado al ámbito de las ciencias educativas, la persona humana, aun con sus limitaciones, es alguien que se interroga por la sociedad, por sí mismo y por las cosas que lo rodean. Así, la enseñanza basada en competencias podría ser una gran oportunidad para realizar una autocrítica personal de capacidades y errores. También podría ser un medio para lograr propulsar la búsqueda, la curiosidad intelectual; es decir, la investigación en la educación. Ya desde el enfoque constructivista, se decía que el alumno es el centro de la educación y que el docente es un orientador y guía. De esta manera, un docente no tiene la última palabra en un tema determinado. El conocimiento se sigue produciendo. De la misma manera, una enseñanza por competencias, al enfatizar los logros deseados y esperados de un aprendizaje, puede despertar la chispa investigativa y la curiosidad intelectual en los alumnos.

Con estos dos fundamentos antropológicos se puede ver que, la educación por competencias, con todas sus potencialidades y debilidades, quiere ser un cambio en cómo se concibe la educación. Dicho cambio tendría que tener repercusiones en la praxis educativa también. No obstante, hay que remarcar que la enseñanza por competencias también ha recibido críticas y cuestionamientos de varios sectores y a continuación se plantean algunas de ellas.

\section{Críticas a la enseñanza por competencias}

Como ya se ha señalado en las líneas anteriores, querer cambiar o modificar la forma de hacer la educación no es tarea fácil. Tampoco es un proceso que se hace en corto tiempo. Al ser un proceso, los cambios educativos serán graduales y lentos e incluso tendrán resistencias. A este punto de las resistencias analizar algunas de las críticas que ha sufrido el enfoque de educación por competencias. Por supuesto, se presentan solamente algunas críticas, sin ánimos de exhaustividad.

Una de las primeras enfatiza que la educación por competencias es limitada, parcial y nunca algo definitiva. En realidad, la enseñanza por competencias pretende ser un enfoque para orientar procesos educativos, pero de ninguna manera es la panacea de todos los problemas escolares o investigativos. De esta manera, según esta postura, la educación por competencias es limitada y por ende, a criterio de un autor "debe asumirse con espíritu crítico flexible, lejos de todo fundamentalismo (Tobón, 2005, p.83).

Otra de las críticas que tiene la enseñanza por competencias es que se ha

La educación con enfoque por competencias: ¿una oportunidad para impulsar la investigación

44. en la universidad? visto como una postura afín a la globalización y a la economía de mercado neoliberal. Como es sabido, gran parte de la economía actual sigue las directrices neoliberales que hablan de un libre mercado y de que el Estado no debe regular las operaciones comerciales. Con esto, de acuerdo con los críticos, 
se estaría dando una visión demasiado comercial a la educación, olvidándose de su dimensión social. Al respecto, una publicación decía lo siguiente:

Las competencias es otra de las nuevas ideologías, que colonizan los sistemas educativos actuales: un proceso neoliberal tendiente a colocar al estudiante al servicio de las necesidades de la economía y del mercado, y no la educación al servicio del estudiante. Se trata de reducir la educación a la fabricación de un alumno económicamente "perfomante", adiestrado para ser competitivo. (Del Rey y Sánchez-Parga, 201 1, p. 235)

En la cita anterior podemos ver que la crítica a la enseñanza por competencias estriba en que ella se presenta como una forma nueva e innovadora de educar pero detrás de eso se esconden unos intereses concretos del mundo económico. En efecto, en algunas naciones como Panamá se dieron protestas ante el gobierno y el Ministerio de Educación cuando estos últimos hablaron de un enfoque por competencias. Opinando personalmente sobre esta crítica, sin duda, considero que es un hecho incuestionable que toda educación nace en un contexto determinado que la nutre y condiciona. Hoy, se hace educación desde un contexto específico y para ciertos intereses. No se puede ser cien por ciento neutro y todo proceso humano está cargado de sentido e intereses múltiples. Puede ser que hoy, al tener la economía un papel preponderante dentro de la sociedad, arrastre a la educación. Sin embargo, a pesar de las críticas y cuestionamientos, la educación por competencias se muestra como una opción válida en un mundo complejizado ya que, estando o no en un mundo neoliberal, la educación debe responder a los retos de su sociedad y de su mundo. Hoy es la economía la dimensión humana que ejerce su peso en la sociedad, mañana quizás lo sea otra ciencia u otro paradigma. Lo interesante es que la educación siempre debe mostrarse competente en su momento y cuestionándose por el tipo de ser humano que quiere formar.

Otra crítica a la educación por competencias es que, según algunos, desvaloriza lo intelectual al enfatizar otras cualidades y capacidades. De esta manera, no se le da importancia a los títulos, diplomas y certificaciones. Para la educación por competencias, los títulos y diplomas serán solamente una competencia entre varias que se pueden tener para desenvolverse en la vida. Esto podría llevar a desvalorizar los estudios que se han realizado con grandes esfuerzos. Aunque dicha crítica pueda tener alguna razón, lo cierto es que desde hace varios años, en educación se viene hablando de "inteligencias múltiples" (Gardner, 1994), sin duda, la personas tiene que desarrollar varias inteligencias a lo largo de su vida y es aquí donde la educación por competencias ha enfatizado que la educación debe desarrollar destrezas en los alumnos. De hecho, el perfil profesional que se espera en un currículo por competencia es que el nuevo profesional sea competente en diversas áreas y sepa responder con varias destrezas al mundo actual que ya de por si se ha complejizado. Aunque los estudios que ofrecen un titulo dan ciertas destrezas, hoy, con la exigencia tan fuerte del mundo actual, el nuevo profesional deberá estarse actualizando constantemente. 
Habrá más críticas hacia la educación por competencias. Aunque estas críticas pueden tener sustento, lo cierto es que la educación y los currículos por competencias forzosamente han logrado poner en la palestra de acción algo que hasta cierto punto ha sido descuidado por la educación universitaria: la investigación. A continuación se plantean algunas reflexiones sobre cómo se podría potenciar la investigación desde un currículo por competencias.

\section{La educación por competencias y la investigación}

Como se ha planteado anteriormente, algunas universidades de El Salvador están implementando el enfoque por competencias en su formación profesional. Eso constituye una muestra de las intenciones de cambio en el ámbito educativo. Ahora bien, en este apartado se puntualiza que la educación por competencias puede ser un medio para estimular y promover la investigación. La Ley de Educación Superior establece que la educación superior integra las funciones de docencia, investigación científica y proyección social (Ley Educación Superior, 1996). Con esto, se enfatiza la obligatoriedad y la necesidad de realizar investigación en la universidad. En una educación con clases tradicionales y con poca participación del alumnado difícilmente se podrá realizar un proceso investigativo, o una investigación centrada en el alumno y no el docente.

Esto es importante porque se ha dicho durante varios años que en Latinoamérica no produce un pensamiento ni una ciencia propia. Casi todo lo que se imparte en las clases es generalmente repeticiones de teorías que se han producido en Europa o Estados Unidos. Lo que a menudo se hace es ver las posibles aplicaciones que un pensamiento foráneo tiene a la realidad local. Igualmente se reclama que América Latina todavía está en "pañales" en la investigación científica. Algunos autores se han atrevido incluso a hablar de un eurocentrismo en la forma en que se hace pensamiento y academia en Latinoamérica (Dussell, 1995). Con la educación con enfoque por competencias podría ir cambiando este tipo de percepciones y realidades.

En un currículo por competencias, la planificación forzosamente poseerá contenidos no solamente conceptuales, sino que los complementará con los contenidos procedimentales y actitudinales. Sin embargo, una educación por competencias irá más allá de los puros conceptos y enfatizará la práctica o posible aplicación que puedan tener los conceptos. Es ahí donde entran los procedimientos y es específicamente en ese momento en donde se puede dar una oportunidad para que al alumno se le pueda despertar la motivación y la curiosidad intelectual.

El enfoque por competencias puede ofrecer un currículo abierto e innovador. No se puede dedicar únicamente a los aprendizajes teóricos. Todos los componentes deben verse como una unidad e interrelacionados. De esta forma, si no se tiene

La educación con enfoque por competencias: ¿una oportunidad para impulsar la investigación

46. en la universidad? internalizado un conocimiento, no se podrán realizar los procedimientos ni la finalidad. Aunque todos los componentes hay que verlos de forma unitaria, el componente de saber hacer (lo procedimental) es fundamental para promover la actitud investigativa del alumno. El docente tiene que ser muy agudo para 
lograr despertar la inquietud investigativa y en esto estribará la diferencia entre los currículos tradicionales (que fundamentalmente promueven el sabe teórico) y el currículo por competencias (el saber, saber hacer, saber convivir). La universidad tendría que ser el lugar privilegiado para que se manifiesten iniciativas investigativas en las sesiones de clase planificadas desde la educación por competencias. Al final de una asignatura, se debería trabajar por el método de proyectos en donde el alumno se enfrente y analice un problema o situación del mundo actual y desde allí, dé su aporte al respecto. De esta manera, los alumnos serán creadores de sus propias soluciones ante una temática compleja.

Ahora bien, la pregunta inicial de este escrito era: ¿La educación por competencias es una oportunidad para impulsar la investigación en las universidades? Ante esto, la respuesta preliminar directa sería que si, ya que es un enfoque integral que no solo enfatiza el saber teórico sino que promueve el saber hacer y el convivir. No obstante, para que el enfoque por competencias promueva e impulse la investigación a nivel universitario sería necesario puntualizar lo siguiente:

Una educación por competencias está orientada en desarrollar las habilidades de los estudiantes para la resolución de problemas en un contexto determinado. ¿Donde se demuestra esto? En la ejecución. Sin duda, la educación por competencias apunta a ejecutar una acción esperada. Las investigaciones en las diferentes materias podrían ser el medio para poder verificar y observar la ejecución y la combinación de habilidades de los estudiantes.

Las instituciones de educación superior deben hacer una revisión a fondo para visualizar si los programas y las áreas curriculares cubren y desarrollan las competencias que se esperan alcanzar al final de una materia o carrera específica. Es decir, se requiere una revisión continua de las materias que se imparten en un plan de estudio para verificar en qué medida se está realizando las competencias esperadas o deseadas al final. A la vez, desde el modelo educativo que tiene cada institución debería de aparecer el enfoque por competencias ligado a los procesos de investigación.

Muchas veces la investigación se ha visto como un esfuerzo del estudiante sobre un tema o problema determinado. A pesar que eso es cierto, el docente también juega un rol fundamental en esto ya que él guía, orienta, revisa y supervisa el trabajo investigativo. De esta manera, el enfoque por competencias exige que se pacten y se digan los criterios de evaluación y de ejecución para de cómo se practicó o ejercitó la competencia y en esto son fundamentales el docente.

El enfoque por competencias no se suscribe solamente a una materia o asignatura de clases. Trasciende las materias en su unidisciplinariedad y se abre a otras formas de crear conocimiento tales como la interdisciplinarieadad o la transdisciplinariedad. He ahí otra manera de realizar investigación dentro de la universidad. Por lo general en una misma universidad hay diferentes departamentos en donde cada cual trabaja en función de su área o razón de ser. El enfoque por competencias podría propiciar a un diálogo, una vinculación 
interdisciplinario para interpretar de diferentes maneras los complejos problemas de la realidad.

Finalmente, el enfoque por competencias, al promover la resolución de problemas, debería al final crear en el estudiante una "actitud investigativa". En efecto, se debe dar el paso de ver la investigación solo con el fin de obtener una nota a valorar la investigación como un estilo de vida. Así, a educación por competencias desarrollaría una curiosidad investigativa que trascienda el aula y la materia.

\section{A modo de conclusión}

Una vez vistas estas reflexiones sobre el enfoque por competencias conviene ahora realizar algunas conclusiones al respecto.

La educación por competencias al igual que otros enfoques quiere responder a una serie de necesidades que tiene la sociedad. No será el único enfoque ni el último que tendremos. Como se ha señalado en la introducción de este ensayo, la educación está en continuo cambio y renovación. Dentro de unos años tendremos un nuevo enfoque, otros paradigmas y así, la educación intentará cambiar para innovar y estar a la altura de su tiempo. Hoy la enseñanza por competencias presenta una serie de fortalezas que permiten poder cambiar hasta cierto punto, la forma en cómo se hace y se aprende. La educación universitaria no se ha quedado al margen de eso y también ha enfatizado la necesidad y pertinencia de una educación por competencias.

La enseñanza por competencias no es un fin, es un medio para lograr aprendizajes innovadores en los educandos. De esta manera, la enseñanza por competencias no quiere ser la última palabra en enseñanza educativa. Tendría hoy en día que escuchar a otras voces y disciplinas para nutrirse e innovarse. Esto conecta con la interdisciplinariedad. En efecto, hoy es común ver que varias instituciones fomentan la interdisciplinariedad para analizar problemas de la sociedad o de las materias. Una ciencia o disciplina no puede ser autosuficiente. Necesita estar en contacto y diálogo con otras ciencias.

La enseñanza y los currículos por competencias son una oportunidad privilegiada para poder despertar la curiosidad intelectual e investigativa en los alumnos. En esto debería diferenciarse las clases planificadas y realizadas desde un enfoque tradicional y las clases planificadas desde un currículo por competencias. Con la enseñanza por competencias se abre un amplio camino para poder realizar procedimientos de exploración e investigación con los alumnos.

La educación con enfoque por competencias: ¿una oportunidad para impulsar la investigación 


\section{Referencias}

Alegre De la Rosa, O. M. y Villar (2006), Competencias para la formación de docentes universitarios. Málaga: Ediciones Aljibe.

Beluche, O. (2013). La educación por competencias y el neoliberalismo. Recuperado en junio de 2016 de http://www.sinpermiso.info/textos/la-educacin-porcompetencias-y-el-neoliberalismo.

Del Rey y Sánchez-Parga (2011). Crítica de la educación por competencias, Revista de Ciencias Sociales y Humanas 15, 233-246.

Dussel, E. (1995). Europa, modernidad y eurocentrismo. Revista Ciclos en la Historia, la Economía y la Sociedad, CLACSO (5)8, 167-178.

Gardner, H. (1994). Estructuras de la mente. La teoría de las inteligencias múltiples. Ciudad: Fondo de Cultura Económica.

Ley de Educación Superior (1996). San Salvador: Editorial Jurídica.

Ministerio de Educación, (2008), Currículo al servicio del aprendizaje: Aprendizaje por competencias. San Salvador

Ministerio de Educación (2005). Plan Nacional de Educación 2021. MINED

Oroz, J. (1988). Finitud y compromiso. Ciudad: Editorial Universidad de Deusto.

Ponce, A. (2014), Educación y lucha de clases. San Salvador: Editorial Jurídica Salvadoreña.

Represa, E. (2009). Las competencias a lo largo de la historia. Recuperado el 13 de mayo de 2016 de http://www.catolica.edu.sv/decanatos/cchh/pensamiento/paginas/ articulos2009/LAS\%20COMPETENCIAS\%2OA\%20LO\%2OLARGO\%2ODE\%2OLA\%20 HISTORIA.pdf

Rodríguez, A. L. (s. f.). El sistema de educación superior en El Salvador" en http://tuning. unideusto.org/tuningal/images/stories/presentaciones/el_salvador_doc.pdf Recuperado el 12 de mayo de 2016.

Sacristán, G. (2008). Educar por competencias, ¿Qué hay de nuevo? Madrid: Editorial Morata.

Tobón, S. (2008). La formación basada en competencias en la educación superior. Recuperado de http://cmapspublic3.inmc.us/rid= 1 LVT9TXFX-1VKCOTM-16YT/ Formaci\%C3\%B3n\%20basada\%20en\%20competencias\%20(Sergio\%20Tob\% C3\% B3n).pdf

Zavala, A. (2007). 11 ideas clave: como aprender y enseñar por competencias. Barcelona: Editorial Grao.

Zubiri, X. (1989). Estructura dinámica de la Realidad. Madrid: Alianza Editorial. 